\title{
Study of the Effect of Plastic Waste Fibers Incorporation on the Behavior of Self Compacting Concrete
}

\author{
Laid Baali $^{1}$, Larbi Belagraa ${ }^{2}$, Mohamed Aziz Chikouche $^{1^{*}}$, Leila Zeghichi ${ }^{3}$ \\ ${ }^{1}$ Laboratory of Materials and Mechanics of Structure, Faculty of Technology, Civil Engineering Department, Mohamed \\ Boudiaf University, PO Box 166 Ichbilia, M'sila 28000, Algeria \\ ${ }^{2}$ Laboratory of Materials and Electronic Systems (LMSE), Bachir Ibrahimi University of Bordj Bou Arreridj, Bordj Bou \\ Arreridj 34000, Algeria \\ ${ }^{3}$ Department of Civil Engineering \& Faculty of Technology \& University of Ahmed Khider, Biskra 7000, Algeria
}

Corresponding Author Email: mohamedaziz.chikouche@univ-msila.dz

https://doi.org/10.18280/acsm.450508

Received: 19 September 2021

Accepted: 12 October 2021

\section{Keywords:}

waste, plastic fibers, SCC, cracking, rheology, mechanical properties

\begin{abstract}
The use of waste and by-products has been for many decades for the manufacturing of building materials such as concrete and mortars. That responds simultaneously to reasons of economy of natural resources in aggregates (C\&D waste) and the possibility of recovering industrial waste additions as replacement in composites. The present study focuses on the use of plastic waste fibers embedded in the cement matrix of selfcompacting concrete SCC to improve its properties, either rheological mainly, the stability at fresh state or mechanical responses such as compressive and tensile strengths at hard state. This incorporation of plastic fiber reinforcement on the structure matrix could result an alternative SCC composite as a ductile material with enhanced properties. In this context, the self-compacting composites by adding a variable percentage of plastic fibers at $0.5,1,1.5 \%$ is formulated. Hence, the effect of plastic fibers waste on the rheological and mechanical properties of SCC is assessed. The obtained results in the present study let us to conclude the beneficial effect of such inclusion of plastic fibers on this new confected SCC fiber composition with acceptable rheological, physical and mechanical properties compared to those of a normal SCC concrete.
\end{abstract}

\section{INTRODUCTION}

Any production or consumption generates waste, which are often associated with the deterioration of our environment. According to the national waste agency, the quantity of the household and similar waste for 2020 is estimated at more than 13.5 million tons. Plastic represents $15.31 \%$ or about 2 million tons. This waste production could double in 2035 to 23 million tons in 2035 [1].

The management and the recovery of certain reusable materials is practiced, but the quality of efficient recycling is still insufficient $[2,3]$.

Manufacture of building materials (binders and concretes) and to achieve structures (embankments and foundations pavement) is practiced throughout the world; in order to limit the excessive exploitation of natural resources and reduce pollution suffered more our environment.

Previous research on the subject reported that addition of industrial wastes into the concrete indicated an outstanding improvement in modulus of rupture, split tensile strength and compressive strength at an early and later ages [3-8].

Recent studies undertaken by Ghernouti et al., Peng, on the fresh and hardened properties of self-compacting concrete (SCC) containing plastic bag waste fibers (PBWF). They concluded the advantageous reuse of plastic waste bag fibers at an optimal percentage; the incorporation of fibers gives a beneficial effect on the characteristics for the optimal constituents dosages; which could result in the improvement of the studied composites behavior at fresh and hardened state [9-14].

In this frame of idea, this study could be a contribution to specify unambiguously self-placing concrete strengthened by the addition of plastic waste. The testing experimental program concerns the study of rheological, physical and mechanical properties of a new material that performances ranks among ordinary concrete and steel reinforced concrete; the self-compacting concrete with fibers reinforcement. This classification is based on the fact that these additions are as fibers that do not have well defined geometrical characteristics and their physical and mechanical properties can be different from the original ones, their implementation in the composites is in a random manner.

Our present work aims to see the effect of plastic fibers waste incorporation in a cementitious matrix for the development of a new composite. In this study, we focus on the effect of random inclusion of fibers on the behavior of selfcompacting concrete at rates of $0.5,1$ and $1.5 \%$.

\section{MATERIALS}

Gravels are crushed and used from the region of Bordj Bou Arreridj. Two fractions of aggregates are used for the composition of SCC (3/8) and (8/15). The sand comes from the edge of Wade Maitar (Bou Saâda). All physical characteristics of aggregates are summarized in Table 1. Sieve 
analysis of aggregates is shown in Figure 1.

Table 1. Characteristics of aggregates

\begin{tabular}{ccccc}
\hline \multirow{2}{*}{ Characteristics } & \multirow{2}{*}{ Dune sand } & \multicolumn{2}{c}{ Gravel } \\
& & $3 / 8$ & $8 / 15$ \\
\hline \multicolumn{2}{c}{ Absolute density } & 2.43 & 2.56 & 2.57 \\
Bulk density & State coward & 1.49 & 1.36 & 1.35 \\
& State compact & 1.64 & $/$ & $/$ \\
Porosity & State coward & 38.6 & 45.4 & 47.64 \\
& State compact & 32.3 & $/$ & $/$ \\
Compactness & State coward & 61.4 & 54.6 & 52.35 \\
& State compact & 67.7 & $/$ & $/$ \\
Sand modulus & S.E.V & 73.1 & $/$ & $/$ \\
\multicolumn{2}{c}{ Water content } & 67.7 & $/$ & $/$ \\
\multicolumn{2}{c}{ Fineness modulus } & 1.2 & 0.80 & 0.53 \\
Water absorption degree & 1.58 & $/$ & $/$ \\
\multicolumn{2}{c}{} & 2.67 & 1.29 & 1.66 \\
\hline
\end{tabular}

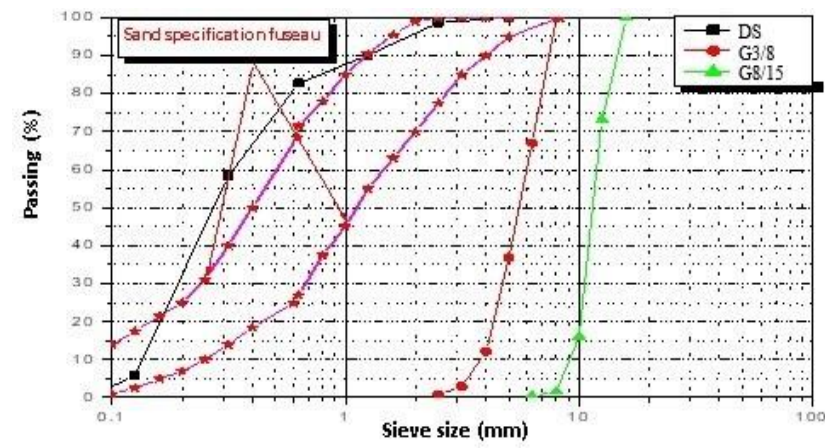

Figure 1. Sieve analysis curve of aggregates

Portland cement used is CEMII A 42.5. Its chemical composition is summarized in Table 2. Physical characteristics are shown in Table 3.

Table 2. Chemical composition of the used cement

\begin{tabular}{cc}
\hline Elements & Content [\%] \\
\hline $\mathrm{SiO}_{2}$ & 17.7 \\
$\mathrm{Al}_{2} \mathrm{O}_{3}$ & 4.6 \\
$\mathrm{Fe}_{2} \mathrm{O}_{3}$ & 2.99 \\
$\mathrm{CaO}$ & 62.7 \\
$\mathrm{MgO}$ & 1.90 \\
$\mathrm{~K} 2 \mathrm{O}$ & 0.67 \\
$\mathrm{Na}_{2} \mathrm{O}$ & 0.05 \\
\hline
\end{tabular}

Table 3. Physical and mechanical properties of the used cement

\begin{tabular}{ccc}
\hline Property & Value & Unit \\
\hline Specific density & 3.1 & $\left(\mathrm{~g} / \mathrm{cm}^{3}\right)$ \\
Fineness & 3950 & $\left(\mathrm{~cm}^{2} / \mathrm{g}\right)$ \\
Initial setting time & $2: 40$ & $\mathrm{H}: \mathrm{mn}$ \\
Final setting time & $4: 20$ & $\mathrm{H}: \mathrm{mn}$ \\
Compressive strength (7 days) & 22.3 & $(\mathrm{Mpa})$ \\
$\begin{array}{c}\text { Compressive strength (28 } \\
\text { days) }\end{array}$ & 48.8 & $(\mathrm{Mpa})$ \\
\hline
\end{tabular}

MEDAPLAST SP40 is a super-high range water reducing plasticizer, to obtain concrete and mortars with high quality. In addition to its main function of super plasticizer, it considerably reduces the water content of the concrete.

The fillers used are limestone from the quarry cement plant of Ain El-Kbira Setif region (300 Km East of Algiers). The physical and chemical characteristics are presented in the Table 4 below.

The waste is a small plastic pieces taken from alimentary big bags. After cleaning and drying in the open air, the cut is made by simple scissors. The Lengths are from $2-2.2 \mathrm{~cm}$, their density is $150\left(\mathrm{Kg} / \mathrm{m}^{3}\right)$, as shown in Figure 2.

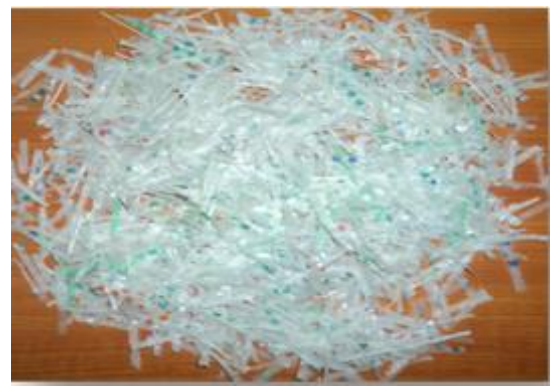

Figure 2. Plastic fibers

Table 4. Chemical composition and physical properties of limestone

\begin{tabular}{|c|c|}
\hline \multicolumn{2}{|c|}{ Chemical composition [\%] } \\
\hline $\mathrm{SiO}_{2}$ & 10.81 \\
\hline $\mathrm{CaO}$ & 47.51 \\
\hline $\mathrm{MgO}$ & 0.21 \\
\hline $\mathrm{Fe}_{2} \mathrm{O}_{3}$ & 0.76 \\
\hline $\mathrm{Al}_{2} \mathrm{O}_{3}$ & 0.31 \\
\hline $\mathrm{CO}_{2}$ & 37.60 \\
\hline $\mathrm{H}_{2} \mathrm{O}$ & 3.09 \\
\hline Carbonates & 85.4 \\
\hline LOI & 40.69 \\
\hline \multicolumn{2}{|c|}{ Physical characteristics } \\
\hline Bulk density $\left(\mathrm{g} / \mathrm{cm}^{3}\right)$ & 0.87 \\
\hline Specific density $\left(\mathrm{g} / \mathrm{cm}^{3}\right)$ & 2.66 \\
\hline Fineness $\left(\mathrm{cm}^{2} / \mathrm{g}\right)$ & 3500 \\
\hline
\end{tabular}

\section{PREPARATION OF SCC}

The formulation of self-compacting concrete was made in accordance of AFGC recommendations (French Association of Civil Engineering AFGC) [7]. Concrete parameters and the compositions of the concrete used in this study are grouped in the Table 5 .

The percentages of fiber were calculated from the volume density of self-compacting concrete witness (Table 6).

Table 5. Parameters set and composition of SCC mixtures

\begin{tabular}{cc}
\hline Property & Value \\
\hline Cement $(\mathrm{Kg})$ & 400 \\
Gravel $(\mathrm{Kg} / \mathrm{m} 3)$ & 850 \\
Sand $(\mathrm{Kg} / \mathrm{m} 3)$ & 850 \\
SP dosage $(\%)$ & 2.25 \\
Fiber/Cement ratio & 0.25 \\
Water/Cement ratio & 0.6 \\
\hline
\end{tabular}

Table 6. The composition of the SCC fibers mixtures

\begin{tabular}{ccc}
\hline Dosage (\%) & Quantity $\left(\mathbf{K g} / \mathbf{m}^{\mathbf{3}}\right)$ & Nomination \\
\hline 0.5 & 0.75 & SCC 0.5P \\
1 & 1.5 & SCC 1P \\
1.5 & 2.25 & SCC $1.5 \mathrm{P}$ \\
\hline
\end{tabular}




\section{RESULTS AND DISCUSSION}

\subsection{The fresh State}

The workability of the SCC is characterized mainly by:

(1) A mobility in a confined medium described by the Flow table test.

(2) A mobility in confined surroundings described by the L box test (rate of filling $\mathrm{H}_{2} / \mathrm{H}_{1}$ ).

(3) A sieve stability test (segregation index).

\subsubsection{Flow table test}

The values of the flow diameter are usually in the range between 50 and $75 \mathrm{~cm}$ for SCC mixtures (Figure 3). The use of plastic fibres in the mixtures of the self compacting concrete is to be discussed later to see their effect as well as the rate of filling on the behaviour of SCCs at fresh state in regards to flow table test and the ability of passage through a confined space by the L-box testing tool. The reduction of the spread out diameter by increasing the percentage of fibres is related mainly to the quantity of water ratio (W/C), the added amount of fibres ask for an additional quantity of water for their damping, when the mobility of the mixture of the concrete incorporating plastic fibers will be affected. The mean diameter D ranges from 55 to $65 \mathrm{~cm}$ for SCCP; however, it is around $70 \mathrm{~cm}$ for control one (without fibers). The minimal diameter is registered for SCC $0.5 \mathrm{P}$ at the value of 55 which is less than $60 \mathrm{~cm}$ the recommended number by the AFGC [7]. For the SCC mixtures with $\mathrm{W} / \mathrm{C}=0.4$, ranges from 61 to 67 $\mathrm{cm}$ spreading diameter, 69 to $74 \mathrm{~cm}$ for $\mathrm{W} / \mathrm{C}=0.5$ and 69 to $70 \mathrm{~cm}$ for mixes with at water cement ratio $\mathrm{W} / \mathrm{C}=0.6$ and higher than this value, respectively.

The obtained values show that most of the tested compositions present an accepted spreading diameter values as recommended by standards for SCC concretes.

The fluidity to be gained in the case of SCC plastic fiber incorporation could be attributed to the use of the higher dosage of super-plastizier as $2.25 \%$ of the weight of the binder for the same ratio of $\mathrm{W} / \mathrm{C}$. Hence a limited flow table diameter of the SCC mixture is noticed, in comparison with the witness Thus, the SCC with fiber incorporation is with lower workability that is related to fibers dosage that limit the fluidity of such mixtures much stickier and with less mobility [11].

One could conclude that the introduction of the plastic fibers has a meaningful effect on the workability of the tested SCC's types $[11,15]$.

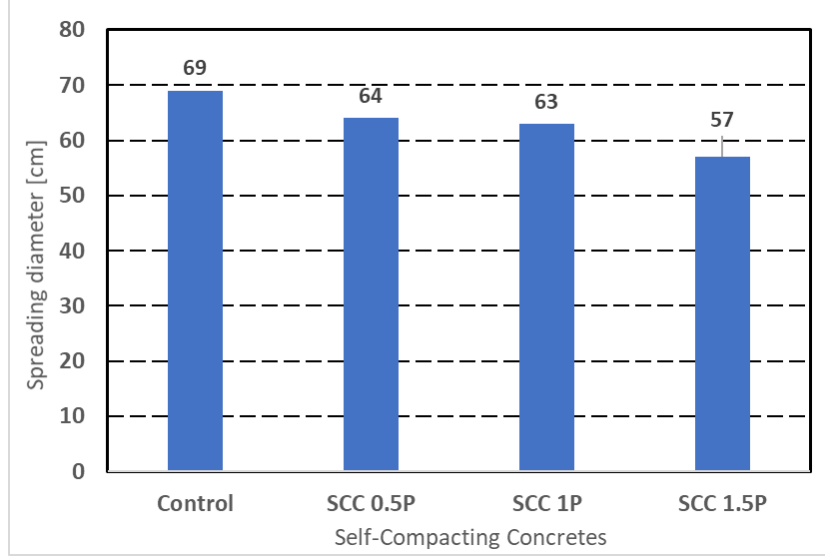

Figure 3. Flow table test results for SCC studied mixtures

\subsubsection{Box test}

Figure 4, shows the results obtained for the L box test. The test is exploited through the occupancy rate relationship of the concrete heights in bottom and in the beginning of the box which must as a rule be upper to 0,8 according to the recommendations [7]. The $\mathrm{SCC} 0 \mathrm{P},(\mathrm{W} / \mathrm{C}=0.6)$ are more fluid than the other concrete types, because of the higher $\mathrm{W} / \mathrm{C}$ ratio. The mixtures with higher fibers content presented occupancy rates being lower to the control mix, one can say that the introduction of the fibers in the cement matrix reaching $1.5 \%$ of fiber content has an effect on the mobility of the SCCs in a confined medium. This reduction is estimated to be around $50 \%$ for a SCC $1.5 \mathrm{P}$ in comparison with control SCC OP one at the same $\mathrm{W} / \mathrm{C}$ ratio $[11,15]$.

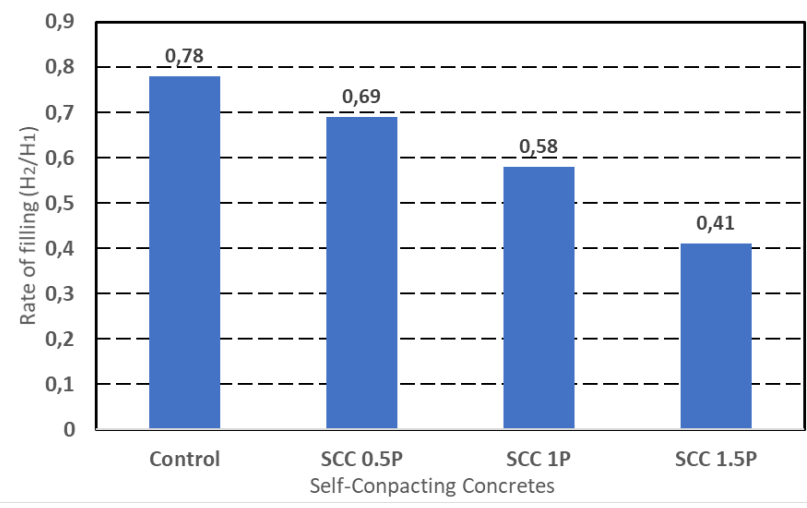

Figure 4. L-box test results for SCC studied mixtures

In the same way mobility in confined surroundings estimated by the L-box test as expressed of the rate of filling of in is affected, the capacity of the flow of the concrete in the zones confined (very reinforced formwork) without vibration east prevents by adding fibres, the fine gravels tend to come in contact the ones with the others, and in the presence of fibres it will be significant. What can be represented on the following figure (Figure 5):

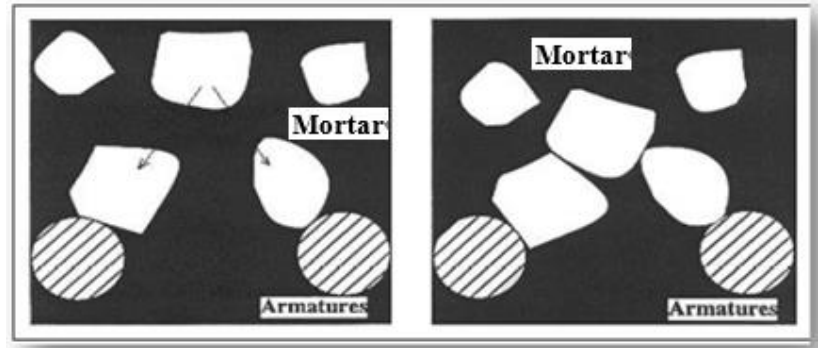

Figure 5. Phenomenon of blocking of the aggregates to the right of an obstacle [7]

The fibres improve resistance to the segregation of the concrete, they offer to the concrete homogeneity and the risk of compressing and sweating of the concrete is limited.

\subsubsection{Segregation index}

The percentage in weight of slurry having crossed the sieve compared with the weight of the initial sample expresses the stability of the concrete. From Figure 6, the results obtained which showed that the SCC's present an index of segregation inferior to $15 \%$ for either the concrete witness mix and other concretes with plastic fiber additions. This reflects a sufficient stability, SCC's having a value of the resistance for the 
segregation lower about $2 \%$ offer a self compacted concrete of very good quality. The fibres improve resistance to the segregation of the concrete, they offer to the concrete homogeneity and the risk of compressing and sweating of the concrete is limited. The due fact is that the introduction of fibers to the composition gives a mixture with a higher water demand to ensure the recommended fluidity, however it contributes on the other side in enhancing the concrete mix homogeneity and limit the segregation phenomenon [14].

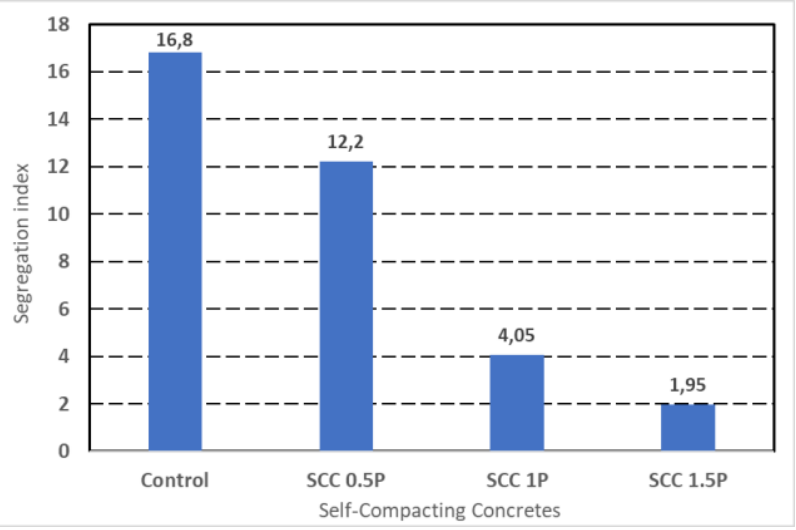

Figure 6. Segregation index test results for SCC studied mixtures

\subsection{The hardened state}

\subsubsection{Compressive strength}

The compressive strength is estimated in 7 days and 28 days of hardening in wet medium and presented in the Figure 7. It can be noted that the incorporation of plastic fibres affects negatively the short-term resistance (7 days) and medium-term (28 days) of SCC-P mixtures.

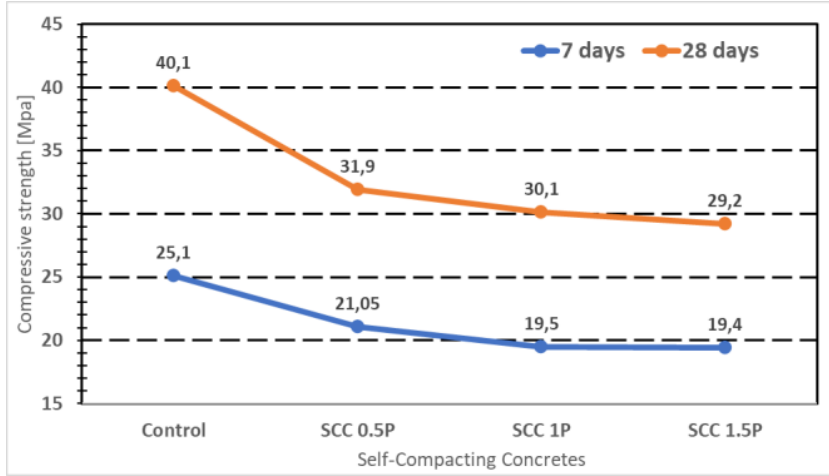

Figure 7. The compressive strength of SCC

The increase in the percentage of fibers has a significant influence on resistance. The values registered for all SCC's compositions with plastic fibers are slightly lower compared to the control mix. These results for SCC $\mathrm{P}$ mixtures are around 20 and $25 \mathrm{MPa}$ for SCC P and reference, successively. The reduction in the compressive strength for all types of SCC plastic fibers is around $20 \%$ when compared to the control one in 7 days.

The same trend is observed for mid-term resistance in 28 days; a maximal value of $40 \mathrm{MPa}$ for control mix (without fibers) is recorded at $0 \%$ percentage compared to SCC $\mathrm{P}$ with fibers at values ranging from 29 to $34 \mathrm{MPa}$. The decrease in strength is about $25 \%$ for SCC P when compared to the witness (without plastic fibers). The mechanical response in compression for all SCCP mixes at 7 and 28 days could be seen as reasonable compared to the normal control concrete and they achieved values about $30 \mathrm{MPa}$ for the whole compositions with fibres. The length/diameter ratio $(1 / \mathrm{d})$ of PBWF does not affect the 28-day compressive strength. The increase in compressive strength is about $7-13 \%$, compared to the reference concrete (RSCC). For WFSCC containing a large amount of fibers, the strain exceeds 50\% compared to RSCC $[11,12,16]$.

\subsubsection{Tensile strength}

The results of tensile strength for studied composition are shown in Figure 8. It can be noted that the use of plastic fiber of $0.5 \%$ and $1 \%$ has slightly improved the tensile strength by splitting for SCCP mixtures. The tensile strength in bending development presents a trend of progressive increases with the rate of plastic fiber added at 7 and 28 days of ade.

Results of tensile strength have shown that the presence of the plastic fibers is advantageous with a gain equal to $9 \%$ compared to SCC mixture without fibers at an optimal dosage of $0.5 \%$. The higher dosages of fibers over $1 \%$ incorporated lead to a decrease in the tensile strength of SCC mixtures at the age of 28 and 45 days. Previous studies on found that the incorporation of waste plastic fibers PBWF in SCC has a positive effect on the split tensile strength value in 28 days. The improvement can reach $74 \%$, it depends on the amount of PBWF, and it is not affected by the length of fibers [11].

The presence of PBWF in SCC prevents the sudden break and increases the fracture toughness of the material; this property can be interesting in terms of security, since even after breaking, the parts of concrete remain attached to each other $[11,12]$.

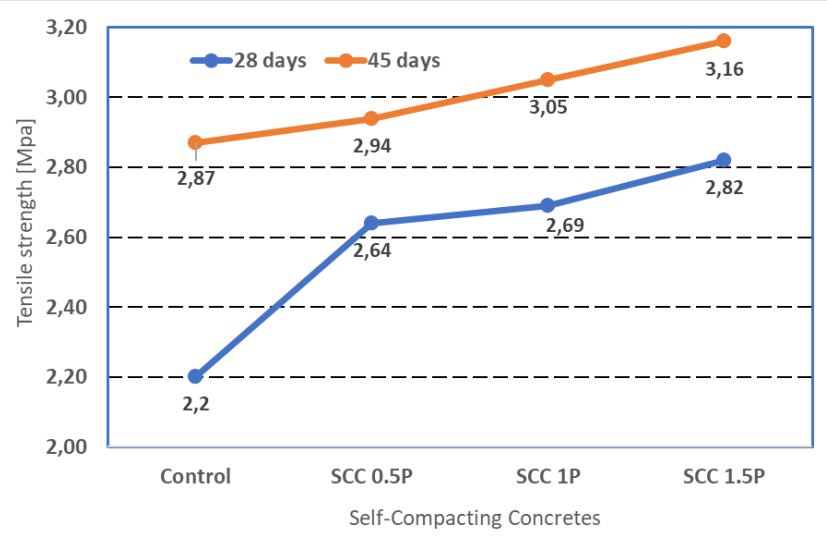

Figure 8. Tensile strength versus plastic fibers dosages for studied SCC mixtures

\section{CONCLUSIONS}

In this study, the main objective was to achieve development with the fibers of plastic waste a formulation that can lead to a self-compacting concrete with acceptable properties similar to a conventional concrete in regards to mechanical response mainly the resistance to compression and strength further to enhanced tensile strength.

The present experimental investigation on the effect of fiber contents on the SCCP characteristics at fresh and hardened state let the following conclusions to be drawn. 
The workability of self-compacting concrete SCCP's is negatively influenced by the incorporation of plastic fibers. The concrete prepared with different dosages of fibers show a significant improvement in the segregation index. This introduction attribute to a better homogeneity of the SCC mixtures.

The L box tests showed a lack of workability and ability in confined area for SCCP with higher dosages of plastic fibers content so a weak filling capability rate attributed mainly to the blocking of aggregates due to the presence of plastic fibers.

The fibers used showed improved resistance to segregation of concrete, they offer a better consistency of concrete limited the risk of bleeding and result in a less segregation phenomenon.

A decrease in resistance to compression for concrete reinforced with plastic fibers regardless of the proposal fibers dosages. The maximal value in 28 days compressive strength is obtained for a $1.5 \%$ content at a percentage around $27 \%$.

Results of tensile strength have shown that the presence of the plastic fibers is advantageous with a gain equal to $9 \%$ compared to SCC mixture without fibers at an optimal dosage of $0.5 \%$.

Finally, it could be concluded that limited optimal dosage less than $1 \%$ of waste fibers incorporation in the SCC composites is advised to have a comprising advantageous effect at fresh and hardened state. Further, the investigation of other properties like the durability, shrinkage of SCC could be proposed to assess the influence for such inclusion of plastic waste fibers based SCC's.

\section{REFERENCES}

[1] Rapport sur l'état de la gestion des déchets en Algérie. (2020). National Waste Agency. Algeria. 151. Available at https://and.dz/site/wpcontent/uploads/rapport\%20DMA2.pdf, accessed on 6 August 2021.

[2] Bode, V.K., Reddy, P.N. (2020). Effect of industrial waste on strength properties of concrete. Annales de Chimie - Science des Matériaux, 44(5): 353-358. https://doi.org/10.18280/acsm.440508

[3] Chen, C., Tang, P., Zhuang, J. (2020). Influence of waste slurry as mixing water on the properties of C80 concrete with different mineral. Annales de Chimie - Science des Matériaux, 44(4): 257-262. https://doi.org/10.18280/acsm.440404

[4] Okamura, H., Ouchi, M. (2003). Self compacting concrete. Journal of Advanced Concrete Technology, 1(1): 5-15.

[5] Ployaert, C., (2005). FEBELCE - Fédération de l'Industrie Cimentière Belge, Brussels, 8. Available at https://www.febelcem.be/fileadmin/user_upload/dossier s-ciment-94-08/fr/36_fr.pdf., accessed on 6 August 2021.

[6] Bibi, M., Benyahia, A., Dahmous, H. (2009). Influence des fibres métalliques sur le comportement mécanique du béton. Algérie Équipement, Équipement, N 45 Mai 2009.

[7] Association Française du Génie Civil. (2008). Recommandations pour l'emploi des bétons auto-plaçant. Available https://www.afgc.asso.fr/app/uploads/afgc/publication/2 1546/recommandations_bap_afgc_finales_vf pages_164.pdf., accessed on 7 August 2021.

[8] Sedran, T. (1995). Les Bétons Autonivelants (BAN) Synthése bibliographique. bulletin LCPC, 196: 53-60.

[9] Okamura, H., Ouchi, M. (2003). Applications of SelfCompacting Concrete in Japan. In: Proceedings of the 3rd International RILEM Symposium on SelfCompacting Concrete, O. Wallevik and I. Nielsson, Ed., RILEM Publications.

[10] Courard, L. (2006). Le cycle de vie des matières: Les matériaux de construction et de démolition. Liège, 36. Available https://orbi.uliege.be/bitstream/2268/258585/1/DEC4_D ossier_20070328.pdf., accessed on 7 August 2021.

[11] Ghernouti, Y., Rabehi, B., Bouziani, Ghezraoui, H., Makhloufi, A. (2015). Fresh and hardened properties of self-compacting concrete containing plastic bag waste fibers (WFSCC). Construction and Building Materials, 82: 89-100. https://doi.org/10.1016/j.conbuildmat.2015.02.059

[12] Al-Hadithi, A.I., Hilal, N.N. (2016). The possibility of enhancing some properties of self-compacting concrete by adding waste plastic fibers. Journal of Building Engineering, 8 : 20-28. http://dx.doi.org/10.1016/j.jobe.2016.06.011

[13] Peng Z. (2021). Performance prediction and mix ratio optimization for multielement green high-performance fiber-reinforced cement matrix composite. Annales de Chimie - Science des Matériaux, 45(1): 59-67. https://doi.org/10.18280/acsm.450108

[14] Rebeiz, K.S., Fowler, D.W. (1996). Flexural strength of reinforced polymer concrete made with recycled plastic waste. ACI Structure Journal, 93(5): 524-530.

[15] Hama, S.M., Hilal, N.N. (2017). Fresh properties of selfcompacting concrete with plastic waste as partial replacement of sand. International Journal of Sustainable Built Environment, 6(2): 299-308. https://doi.org/10.1016/j.ijsbe.2017.01.001

[16] Senthil Kumar, K., Baskar, K. (2014). Recycling of Eplastic waste as a construction material in developing countries, Journal of Material Cycles and Waste Management, 17(4): 718-724. https://doi.org/10.1007/s10163-014-0303-5 